\title{
Mental and psychological conditions, medical comorbidity and functional limitation: differential associations in older adults with cognitive impairment, depressive symptoms and co-existence of both
}

José C. Millán-Calenti, Ana Maseda, Sophie Rochette, Gustavo A. Vázquez, Alba Sánchez and Trinidad Lorenzo

Gerontology Research Group, Faculty of Health Sciences, University of A Coruña, Spain

Objective: Cognitive impairment and depressive symptoms are common among the geriatric population but the co-occurrence of both is rarely studied. The purpose of this study was to identify and compare the factors associated with three groups of elderly people: those assessed with cognitive impairment alone (COG), depressive symptoms alone (DEP) or co-existence of both (COG-DEP).

Methods: The cross-sectional study included 600 community-dwellers ages 65 and older. All participants underwent a comprehensive evaluation. Global cognition was measured by the Mini-Mental State Examination (MMSE) and depressive symptoms were defined by the Geriatric Depression Scale (GDS). Specific chronic illnesses relevant to the Charlson comorbidity index (CCI) were self-reported. Functional status was evaluated by the Katz' basic (ADL) and Lawton's instrumental (IADL) activities of daily living scales.

Results: COG-DEP was explained by IADL dependence (OR: 11.9, 95\% CI: 4.59-30.78), ADL dependence (OR: 11.5, 95\% CI: 5.59-23.69), cerebrovascular disease (OR: 3.6, 95\% CI: 1.48-8.68), congestive heart failure (OR: 3.4, 95\% CI: 1.77-6.59) and diabetes (OR: 2.6, 95\% CI: 1.30-5.18), but it was best predicted by functional limitations in the adjusted model. Being functionally dependent and medically ill with shorter life expectancy was shown to significantly increase the odds of being DEP. Functional limitation in IADL was without distinction associated to COG, DEP and COG-DEP.

Conclusion: The present results on COG, DEP and COG-DEP show the particular relevance of certain medical comorbidities and functional limitations to those three distinct groups of elderly people.

Key words: cognitive impairment; geriatric depression; medical comorbidity; functional limitation; life expectancy; elderly people 


\section{Introduction}

As long as mortality in old age continues to fall and fertility remains low, the proportion of older persons will continue to increase. The percentage of the Spanish population aged 60 years and older represents $22.2 \%$ of the whole population (United Nations, 2009). Due to senescence, elderly people are at a particularly high risk of developing illnesses related to aging, not to mention cognitive impairment, which has been shown to affect $22.2 \%$ of the elderly population (Millán-Calenti et al., 2009).

Research has shown that cognitive decline, reaching the threshold for dementia, affects a large proportion of elderly in-patients and is associated with certain alterations (Holstein et al., 1994), the treatment of which is complicated by the mental state of this segment of the population, as missed diagnosis and self-neglect are likely (Wolf-Klein et al., 1988; Löppönen et al., 2004). According to the most recent studies, the number of comorbid conditions seems to be similar in demented and non-demented subjects, but certain chronic medical conditions have been shown to be differentially associated with the cognitively impaired as compared to the unimpaired (Zekry et al., 2008). For example, heart disease, stroke and diabetes have been reported to be associated with cognitive impairment (Breteler et al., 1994; Ferrucci et al., 1996; Strachan et al., 1997). Not only the presence of medical conditions but also declines in the ability to perform certain activities considered important in independent functioning (e.g. activities of daily living (ADL) and instrumental activities of daily living (IADL)) were shown to be associated with cognitive impairment (Bassett and Folstein, 1991; Artero et al., 2001).

It has been observed that a large proportion of cognitively impaired geriatric out-patients have been diagnosed with depression. However, the rate of coexisting depression decreased significantly with increasing severity of cognitive impairment: $33 \%$ of mildly impaired patients were depressed, compared with $23 \%$ of moderately impaired and $12 \%$ of severely impaired (Reifler et al., 1982). Depressive symptoms (referring to mood and affective syndromes rather than clinical depression, which fulfils rigorous diagnostic criteria) were shown to be more frequent among the non-clinical population of elderly people (Zung, 1967) and to similarly co-exist with cognitive impairment. It has been shown that some diseases that alter biological systems can play a role in the development of specific psychological disturbances. Depressive symptoms are highly prevalent in patients with congestive heart failure (Charlson and Peterson, 2002), but the link between cognitive impairment coexisting with depression and chronic illnesses is unclear. The same can be reported for other important limitations, like the ability to perform ADL and IADL (Armenian et al., 1998).

Cognitively impaired and/or depressed elderly people are likely to experience different medical conditions and functional limitations, and thus may have different health care needs. In this study examining a large sample of community-dwelling older adults, we sought to identify and compare the factors associated with three groups of elderly people: those assessed with cognitive impairment alone (COG), depressive symptoms alone (DEP) and coexistence of both (COG-DEP). That is to say, we wanted to primarily determine whether certain medical comorbidities and functional limitations were similarly associated to COG, DEP and COG-DEP and then examine the independent effect of those variables on COG, DEP and COG-DEP by use of a multivariate model.

\section{Methods}

\section{Selection and description of participants}

Data for this study came from a representative sample (N 1/4 600) of community-dwelling residents of Narón Council (A Coruña, Spain), aged 65 years and older. The subjects were selected from the municipal register using a random number table, arranged by age quinquennia and sex. In the sample, mean \pm standard deviation (SD) age was $75.1 \pm 7.5$ years $(75.9 \pm 8.0$ years for women and $73.9 \pm 6.7$ years for men). The level of confidence was $95 \%$, sampling error $\pm 4 \%$ and estimation for data losses $10 \%$.

\section{Procedure}

The study protocol was approved by the Ethics Committee at the University of A Coruña. Participants were individually assessed in a health centre, or at home in the case of people with mobility difficulties. Before the data collection, all participants were informed about the study and signed the corresponding informed consent form.

\section{Variables and instruments}

Cognitive status was assessed by a psychologist using the Mini-Mental State Examination (MMSE) (Folstein et al., 1975). This questionnaire includes items assessing five cognitive domains, with a maximum score of 30 corresponding to the best cognitive status and a cut-off score of 23 or less 
indicating cognitive impairment (COG). However, it is widely accepted that this cut-off score must be varied according to age and educational level, particularly when assessing elderly populations (Morgado et al., 2010). Crum et al. (1993) examined the distribution of the MMSE score according to age and educational level and defined cutoff median scores according to those criteria. In this paper, cognitive impairment is defined according to Crum's cut-off median scores. The score was treated as a continuous variable in multivariate analysis. The acceptance rate to undergo the MMSE test was $98.5 \%$. Nine subjects with minimal level of consciousness were excluded from the random sample as they were unable to be assessed by the MMSE.

Depressive symptoms were also assessed by a psychologist, using the short-form of the Geriatric Depression Scale (GDS-SF) (Sheikh and Yesavage, 1986). This questionnaire was scored to yield a continuous scale from 0 to 15 , with a score of 6 or higher indicating probable clinical depression (DEP) (Herrmann et al., 1996). Due to data losses, 12 additional individuals were excluded from the study.

The standardized Older Americans Resources and Services (OARS) questionnaire (Duke University, 1978) was used to assess socio-demographic and general health status variables. Medical histories were collected by a physician or a trained nurse in charge of the participant during the research. Participants' report was given by the patient or their relatives according to medical records. Comorbidity conditions were defined according to the Charlson comorbidity index (CCI) (Charlson et al., 1987). The weighted index taking into account both the number and the seriousness of comorbid diseases served to calculate a comorbidity score. A composite comorbidity-age score was created by adding to the comorbidity score an age points coded in decades. The composite comorbidity-age score was then used to calculate a 10-year survival expectancy estimation for each participant in a low-risk population.

Functional status was measured using the ADL (Katz et al., 1963) and IADL (Lawton and Brody, 1969) scores. Participants were asked by a physician or a trained nurse if they had any difficulty performing each task without the help of another person. Individuals who were unable to perform any one of the activities were considered to be functionally incapacitated in that activity (ADL or IADL dependent). With regard to the remaining pathologies suffered (personal background and illnesses), data were obtained from the participants' report, collecting the answers given by the patient or their relatives according to the medical records.

\section{Statistical analysis}

Analyses assessed the prevalence of cognitive impairment and depressive symptomatology, and the related sociodemographic, comorbidity illnesses and functional status variables. Spearman's correlation coefficient (r) was used to analyse the association between quantitative variables. The crude odds ratio (OR) measured the association for dichotomous variables of nominal level or higher. Categorical differences were tested with Chi-square $\left(x^{2}\right)$ analysis, and continuous variables were compared using the Kruskal-Wallis test. To adjust for the confounding effect of variables correlated with each other, multinomial logistic regression assessing cognitive functioning, depressive symptoms and both was then used. The model estimated the independent effect of each correlate, and the odds ratios (OR) along with their $95 \%$ confidence intervals (CI) were calculated. Statistical significance was set at $\mathrm{p}<0.05$. Statistical analyses were performed using the SPSS statistical package version 16.0.1 (SPSS Inc., 2007).

\section{Results}

\section{Co-occurrence of cognitive impairment and depressive symptoms}

In the sample used for this study the mean tstandard deviation (SD) for cognitive performance, according to the MMSE scale, was $23.9 \pm 5.6$, and that for the number of depressive symptoms, as measured by the GDS-SF scale, was 3.9 \pm 3.3 . We found that cognitive performance was negatively correlated to the amount of depressive symptoms (Spearman correlation $r$ $1 / 4-0.3, p<0.001)$. As shown in Table $1,12.6 \%$ of the participants were found to have cognitive impairment alone (COG), without depressive symptoms, and $17.3 \%$ were assessed with depressive symptomatology alone (DEP), without cognitive impairment. Considering full independence of the variables, we would have expected $5.2 \%$ of the sample to report both (COG-DEP), but in fact nearly $7.9 \%$ did (OR 1/4 2.3 (1.48-3.49)).

Table 2 presents the characteristics of the sample as a function of cognitive status and/or depressive symptoms of the participants. The oldest subjects (285 years) were more COG (29.4\%) and presented more COG-DEP (22.1\%) than the rest of the population. Those cognitive and psychological afflictions, predominantly DEP, affected women primarily $(22.7 \%)$ and particularly those with no formal education (19.3\%). Those solely DEP and those COG-DEP were also more medicated, with $26.5 \%$ of 
the participants consuming more than six drugs when DEP and $15.7 \%$ when COG-DEP $\left(x^{2} 1 / 438.4,9\right.$ df, $p$ $<0.001)$.

Medical comorbidity, functional limitation and risk of cognitive and/or depressive disorders

In Table 2, solely COG and solely DEP participants were shown to suffer similar average amount of diseases (5.8 and 5.6, respectively), as assessed in the composite Charlson comorbidity-age score. COGDEP participants reported a higher average amount of disease according to age, 6.5 . Solely COG and solely DEP participants were shown to have comparable mean predicted 10-year survival expectancies (2.3 and 2.0 years, respectively), which was greater than the mean for COG-DEP participants: 1.6 years. Participants without cognitive impairment and depressive symptoms were on average healthier and had a higher life expectancy. Notably, as disparity in the sample is very important, the accuracy of those values should be viewed cautiously.

Table 1 Co-occurrence of cognitive impairment and depressive symptomatology

GDS-SF

\begin{tabular}{lccc} 
& No depressive symptoms & Depressive symptoms & Total \\
\cline { 2 - 4 } & $\mathrm{N}(\%)$ & $\mathrm{N}(\%)$ & $\mathrm{N}(\%)$ \\
\hline MMSE & & & \\
No cognitive impairment & $360(62.2)$ & $100(17.3)$ & $460(79.5)$ \\
Cognitive impairment & $73(12.6)$ & $46(7.9)$ & $119(20.5)$ \\
Total & $433(74.8)$ & $146(25.2)$ & $579(100.0)$ \\
\end{tabular}

MMSE, Mini-Mental State Examination; GDS-SF, Short-form of the Geriatric Depression Scale.

Prevalence odds ratio 1/42.3 (1.48-3.49).

As shown in Table 3, elderly people with cancer were 3.7 times more likely to be solely COG than be without cognitive impairment and depressive symptoms (with cancer referring to any malignancy, including those that spread to the brain). Subjects solely DEP differed in terms of limitations and diseases, with the most common ailments concerning: visual limitation (OR 2.5, 95\% CI 1.24-4.91), connective tissue (OR 3.6, 95\% CI 1.78-7.11), peripheral vascular (OR 1.9, 95\% CI 1.20-2.97) and ulcer (OR 1.9, 95\% CI 1.20-3.06) diseases. Additionally, people limited visually (OR 3.9, 95\% CI 1.72-8.78) and auditorily (OR 2.8, 95\% CI 1.38-5.57) and those suffering, from dementia (OR 16.3, 95\% CI 1.45-186.66), cerebrovascular disease (OR 3.6, 95\% CI 1.48-8.68), congestive heart failure (OR 3.4, 95\% CI 1.77-6.59) and diabetes (OR 2.6, 95\% CI $1.30-5.18$ ), were found to be significantly more likely to be COG-DEP.

Concerning functional disability, participants assessed with cognitive and/or depressive disorders in Table 3 were all dependent in instrumental (IADL) and basic (ADL) activities of daily living. Elderly people dependent in IADL were 4.4 times more likely to be solely COG, 2.2 times more likely to be solely DEP and 11.9 times more likely to be COG-DEP. Participants dependent in ADL were almost four times more likely to be COG-DEP rather than solely COG or DEP, which was significant at the $\mathrm{p} 1 / 40.001$ level.

\section{Multivariate analysis}

Many of the variables examined in Table 3 may be correlated with each other. Thus, the multinomial logistic regression analysis presented in Table 4 was used to control for confounding effects. After fitting the multinomial logistic regression, the apparent association based on crude odds ratio for sex and cognitive and/or depressive disorders remained significant at $p<0.05$. Age was no longer associated to COG-DEP, and it was marginally significant for solely COG and solely DEP. In this study, educational attainment was not associated to cognitive and/or psychological functioning when cognitive impairment was defined by a cut-off score based on age-and education-specific norms. 
Table 2 Characteristics of elderly patients with cognitive impairment alone (COG), depressive symptoms alone (DEP) and co-existence (COG-DEP) or not (NCOG-NDEP) of cognitive impairment and depressive symptoms

\begin{tabular}{|c|c|c|c|c|c|c|}
\hline & NCOG-NDEP & COG & DEP & COG-DEP & & \\
\hline & $n=360$ & $\mathrm{n}=73$ & $\mathrm{n}=100$ & $\mathrm{n}=46$ & & \\
\hline & $\mathrm{N}(\%)$ & $\mathrm{N}(\%)$ & $\mathrm{N}(\%)$ & $\mathrm{N}(\%)$ & $x_{2}$ & df \\
\hline \multicolumn{7}{|l|}{ Age } \\
\hline $65-74$ & 227 (70.5) & $24(7.5)$ & $61(18.9)$ & $10(3.1)$ & $65.3^{* *}$ & 6 \\
\hline $75-84$ & $108(57.2)$ & $29(15.3)$ & $31(16.4)$ & $21(11.1)$ & & \\
\hline 285 & $25(36.7)$ & $20(29.4)$ & $8(11.8)$ & $15(22.1)$ & & \\
\hline \multicolumn{7}{|l|}{ Sex } \\
\hline Men & $194(76.6)$ & $24(9.5)$ & $26(10.3)$ & $9(3.6)$ & $42.3^{* *}$ & 3 \\
\hline Women & $166(51.0)$ & $49(15.0)$ & $74(22.7)$ & 37 (11.3) & & \\
\hline \multicolumn{7}{|l|}{ Educational level } \\
\hline No formal education & $289(59.4)$ & $63(12.9)$ & $94(19.3)$ & $41(8.4)$ & $14.2^{*}$ & 6 \\
\hline Primary & $55(79.7)$ & $7(10.2)$ & $5(7.2)$ & $2(2.9)$ & & \\
\hline$>=$ Secondary & $14(77.8)$ & $2(11.0)$ & $1(5.6)$ & $1(5.6)$ & & \\
\hline \multicolumn{7}{|l|}{ IADL dependence } \\
\hline Absent & $213(77.2)$ & $18(6.5)$ & $40(14.5)$ & $5(1.8)$ & $61.9 * *$ & 3 \\
\hline Present & $147(48.5)$ & $55(18.2)$ & $60(19.8)$ & $41(13.5)$ & & \\
\hline \multicolumn{7}{|l|}{ ADL dependence } \\
\hline Absent & $282(72.1)$ & $42(10.8)$ & $56(14.3)$ & $11(2.8)$ & $68.5^{* *}$ & 3 \\
\hline Present & $78(41.5)$ & $31(16.5)$ & $44(23.4)$ & $35(18.6)$ & & \\
\hline \multicolumn{7}{|l|}{ Visual limitations } \\
\hline No & $336(64.1)$ & $67(12.8)$ & 85 (16.2) & $36(6.9)$ & $15.0^{*}$ & 3 \\
\hline Yes & $24(43.6)$ & $6(10.9)$ & $15(27.3)$ & $10(18.2)$ & & \\
\hline \multicolumn{7}{|l|}{ Hearing limitations } \\
\hline No & $311(64.1)$ & $58(12.0)$ & $84(17.3)$ & $32(6.6)$ & $9.6^{*}$ & 3 \\
\hline Yes & $49(52.1)$ & $15(16.0)$ & $16(17.0)$ & $14(14.9)$ & & \\
\hline \multicolumn{7}{|l|}{ Number of medication } \\
\hline $0-1$ & $111(75.0)$ & $20(13.5)$ & $14(9.5)$ & $3(2.0)$ & $38.4 * *$ & 9 \\
\hline $2-3$ & $112(64.3)$ & $25(14.4)$ & $24(13.8)$ & $13(7.5)$ & & \\
\hline $4-5$ & $90(58.1)$ & $16(10.3)$ & $35(22.6)$ & $14(9.0)$ & & \\
\hline 26 & $47(46.1)$ & $12(11.7)$ & $27(26.5)$ & $16(15.7)$ & & \\
\hline \multirow{3}{*}{$\begin{array}{l}\text { Composite comorbidity-age score } \\
\text { Predicted } 10 \text {-year survival } \\
\text { expectancy (years) }\end{array}$} & Mean \pm SD & Mean \pm SD & Mean \pm SD & Mean \pm SD & $x_{2}$ & df \\
\hline & $5.0 \pm 1.6$ & $5.8 \pm 2.0$ & $5.6 \pm 1.6$ & $6.5 \pm 2.2$ & $30.8 * *$ & 3 \\
\hline & $3.2 \pm 3.0$ & $2.3 \pm 2.9$ & $2.0 \pm 2.6$ & $1.6 \pm 2.6$ & $30.8^{* *}$ & 3 \\
\hline
\end{tabular}

Categorical variables: data expressed as number of cases $(\%)$ ( $p$-value of Chi-square test comparing four groups). Continuous variables: data expressed as mean \pm $\mathrm{SD}$ ( $\mathrm{p}$-value of Kruskal-Wallis test comparing four groups). $* p<0.05$. $* * p<0.001$.

For the solely COG, limitations in instrumental functional autonomy remained significant in Table 4 at the $\mathrm{p}<0.001$ level when all possible confounders were controlled for simultaneously, whereas limitations in basic functional autonomy was no longer associated. All the correlates that were associated with DEP alone in the unadjusted analyses remained significant in the full-adjusted model. There was a significant decrease in 10year survival expectancy (OR 0.3, 95\% CI 0.09-0.65) for those DEP. Being a woman (OR 3.2, 95\% CI 1.87-5.43), having limitations in IADL (OR 2.5, 95\% CI
1.46-4.31) and ADL (OR 1.9, 95\% CI 1.14-3.16) increased the risk ofDEP alone. For elderlypeople, the independent effects of limitations in instrumental and basic functional autonomy persisted in their relation to COG-DEP after adjusting for the other correlates. Elderly women (OR 4.3,95\% CI1.89-9.96) with limitations in IADL(OR 6.7, 95\% CI 2.30-19.56) and ADL (OR 4.6, 95\% CI 2.07- 10.20) were more likely to experience COG-DEP. 
Table 3 Cognitive impairment (COG), depressive symptoms (DEP) and both coexisting (COG-DEP), and risk estimates of sociodemographics, functional status and medical comorbidities

\begin{tabular}{|c|c|c|c|}
\hline & COG $(n=73)$ & $\operatorname{DEP}(n=100)$ & COG-DEP $(n=46)$ \\
\hline & $\mathrm{OR}^{\mathrm{a}}(95 \% \mathrm{Cl})$ & $\mathrm{OR}_{\mathrm{a}}(95 \% \mathrm{Cl})$ & $\mathrm{OR}_{\mathrm{a}}(95 \% \mathrm{Cl})$ \\
\hline \multicolumn{4}{|l|}{ Age } \\
\hline 285 (vs. 65-74) & $7.6(3.67-15.59)^{* *}$ & $1.2(0.51-2.77)$ & $13.6(5.54-33.52) * *$ \\
\hline 75-84 (vs. 65-74) & $2.5(1.41-4.57)^{*}$ & $1.1(0.66-1.74)$ & $4.4(2.01-9.70)^{* *}$ \\
\hline Sex (Female vs. male) & $2.4(1.40-4.06)^{*}$ & $3.3(2.03-5.44)^{* *}$ & $4.8(2.25-10.25)^{* *}$ \\
\hline \multicolumn{4}{|l|}{ Educational level } \\
\hline $\begin{array}{l}\text { >=Secondary (vs. no formal } \\
\text { education) }\end{array}$ & $0.7(0.15-2.96)$ & $0.2(0.03-1.69)$ & $0.5(0.06-3.93)$ \\
\hline $\begin{array}{l}\text { Primary (vs. no formal } \\
\text { education) }\end{array}$ & $0.6(0.25-1.34)$ & $0.3(0.11-0.72)^{*}$ & $0.3(0.06-1.09)$ \\
\hline IADL dependence & $4.4(2.50-7.85) * *$ & $2.2(1.38-3.42)^{*}$ & $11.9(4.59-30.78) * *$ \\
\hline ADL dependence & $2.8(1.78-4.54) * *$ & $2.7(1.58-4.52) * *$ & $11.5(5.59-23.69) * *$ \\
\hline Visual limitations & $1.3(0.49-3.19)$ & $2.5(1.24-4.91)^{*}$ & $3.9(1.72-8.78)^{*}$ \\
\hline Hearing limitations & $1.6(0.86-3.12)$ & $1.2(0.65-2.23)$ & $2.8(1.38-5.57)^{*}$ \\
\hline \multicolumn{4}{|l|}{ Number of medication } \\
\hline$>=6($ vs. $0-1)$ & $1.4(0.64-3.13)$ & $4.6(2.20-9.45) * *$ & $12.6(3.50-45.28)^{* *}$ \\
\hline $4-5$ (vs. $0-1)$ & $1.0(0.48-2.01)$ & $3.1(1.56-6.08)^{*}$ & $5.8(1.60-20.65)^{* *}$ \\
\hline 2-3 (vs. $0-1$ ) & $1.2(0.65-2.36)$ & $1.7(0.84-3.45)$ & $4.3(1.19-15.49) * *$ \\
\hline \multicolumn{4}{|l|}{ Diseases assessed in the $\mathrm{CCl}$} \\
\hline Myocardial infarction & $0.6(0.28-1.48)$ & $0.9(0.47-1.74)$ & $1.3(0.56-2.89)$ \\
\hline Congestive heart failure & $1.2(0.59-2.24)$ & $0.9(0.46-1.63)$ & $3.4(1.77-6.59)^{* *}$ \\
\hline Peripheral vascular disease & $1.7(1.00-2.76)$ & $1.9(1.20-2.97)^{*}$ & $1.2(0.63-2.14)$ \\
\hline Cerebrovascular disease & $2.1(0.88-4.95)$ & $1.9(0.85-4.18)$ & $3.6(1.48-8.68)^{*}$ \\
\hline Dementia & $26.4(3.04-229.49) * *$ & $7.3(0.66-81.64)$ & $16.3(1.45-183.66)^{*}$ \\
\hline Chronic pulmonary disease & $1.0(0.49-1.99)$ & $1.1(0.63-2.06)$ & $1.3(0.62-2.95)$ \\
\hline Connective tissue disease & $0.7(0.42-1.22)$ & $3.6(1.78-7.11) * *$ & $1.9(0.85-4.16)$ \\
\hline Ulcer disease & $0.6(0.30-1.15)$ & $1.9(1.20-3.06)^{*}$ & $0.9(0.46-1.93)$ \\
\hline Liver disease mild & $2.1(0.85-5.36)$ & $0.6(0.18-2.17)$ & $0.5(0.06-3.45)$ \\
\hline Diabetes & $1.2(0.59-2.31)$ & $1.1(0.66-2.08)$ & $2.6(1.30-5.18)^{*}$ \\
\hline Cancer & $3.7(1.14-12.03) *$ & $0.5(0.06-4.19)$ & $1.1(0.14-9.32)$ \\
\hline
\end{tabular}

IADL, Instrumental Activities of Daily Living; ADL, Basic Activities of Daily Living.

CCI, Charlson Comorbidity Index.

aOR $1 / 4$ crude odds ratio (CI $1 / 4$ confidence interval).

*Significant correlations are indicated in bold $p<0.05$.

$* * p<0.001$.

\section{Discussion}

The rate for depressive symptoms among older adults is consistent but slightly higher than the average prevalence of depressed older adults in a worldwide community-based study, yielding 13.5\% (Beekman et al., 1999). An explanation for the difference observed may be that the study did not use the same instruments for depressive assessments. In our case, depression was measured using a self-report rating scale and the results pertained to clinically relevant syndromes rather than depressive disorders as defined in the DSM-IV-TR classification (American Psychiatric Association, 2001). However, depressive syndromes not fulfilling rigorous diagnostic criteria are highly prevalent in older adults, while their consequences have been shown to be similar to those of major depressive illness (Wells et al., 1989; Beekman et al., 1997).

Depression is a common feature of cognitive impairment in older age (Forsell et al., 2003;
Gabryelewicz et al., 2004). Our findings are consistent with these studies, suggesting that cognitive impairment and depressive symptoms coexist for $7.9 \%$ of the sample. Whether depressive symptoms are a reaction to cognitive deficits or constitute an early symptom of neurodegeneration is unclear. Some studies have suggested that depressive symptoms follow the onset of dementia (Chen et al., 1999; Vinkers et al., 2004). Conversely, research on the glucocorticoid cascade in the hippocampus have shown that older depressed adults with high or rising cortisol levels during 5 years have poorer memory and greater hippocampal atrophy (Lupien et al., 1998). These findings have been supported by studies that show that cognitive function can improve when depressive symptoms are treated (Bulbena and Berrios, 1993), although some degree of cognitive impairment may remain even after recovery (Marcos et al., 1994; Kessing, 1998). An alternative explanation was that the symptoms of cognitive deterioration may partially overlap with the symptoms of 
depression, and the underlying neuropathological condition that causes cognitive impairment also causes depressive symptoms (Barnes et al., 2006; Panza et al., 2010). Due to the high prevalence of depression in cognitive decline and their common adverse consequences such as apathy, agitation and social withdrawal, screening for depression and cognitive impairment remains an important challenge for psychogeriatric medicine (Lyketsos et al., 2000).

Solely COG, solely DEP or both simultaneously (COG-DEP) have been associated to certain sociodemographic characteristics. In contrast to other authors (Luck et al., 2010; Morgado et al., 2010) we did not find a clear relationship of cognitive function with age and low educational attainment, most likely because in our study cognitive impairment was based on both variables so that discrepancies on age and education were minimized (Crum et al., 1993). Meanwhile, being a woman has been reported to be independent correlate of COG, DEP or COG-DEP and many authors agree on the fact that women in the general population suffer from more depressive symptoms than men (Kockler and Heun, 2002). It has been suggested that risk factors were rather associated to biological sex, as the impact of gender on psychological health was demonstrated not to vary across societies whether they were promoting an egalitarian culture between men and women or not (Zunzunegui et al., 2007). As cognitive impairment and depression are closely related, differences in sex were also observed for the COG and the COG-DEP elderly people, although it could be argued that COG and COG-DEP may be better explained by the worse physical state observed in older women (Agüero-Torres et al., 2002; Millán-Calenti et al., 2010).

Table 4 Multinomial logistic regression model predicting the effect of functional limitation and survival expectancy, as a function of medical comorbidities, on cognitive impairment (COG), depressive symptoms (DEP), and both coexisting (COG-DEP), adjusting for sociodemographics

\begin{tabular}{|c|c|c|c|}
\hline & $\operatorname{COG}(n=73)$ & $\operatorname{DEP}(n=100)$ & COG-DEP $(n=46)$ \\
\hline & $\mathrm{OR}_{\mathrm{a}}(95 \% \mathrm{Cl})$ & $\mathrm{OR}_{\mathrm{a}}(95 \% \mathrm{Cl})$ & $\mathrm{OR}_{\mathrm{a}}(95 \% \mathrm{Cl})$ \\
\hline emale vs, male) & $1.1(1.03-1.13) *$ & $0.9(0.89-0.98)^{*}$ & $1.0(0.99-1.11)$ \\
\hline \multicolumn{4}{|l|}{ Education } \\
\hline $\begin{array}{l}\text { >= Secondary (vs. no formal education) } \\
\text { Primary (vs. no formal education) } \\
\text { IADL dependence } \\
\text { ADL dependence } \\
\text { 10-year survival expectancy }\end{array}$ & $\begin{array}{l}1.3(0.26-6.67) \\
1.1(0.45-2.75) \\
3.4(1.72-6.54)^{* *} \\
1.2(0.65-2.22) \\
2.7(0.83-8.48)\end{array}$ & $\begin{array}{l}0.5(0.06-4.20) \\
0.5(0.17-1.23) \\
2.5(1.46-4.31)^{*} \\
1.9(1.14-3.16)^{*} \\
0.3(0.09-0.69)^{*}\end{array}$ & $\begin{array}{c}2.1(0.18-22.95) \\
0.8(0.16-3.75) \\
6.7(2.30-19.56)^{*} \\
4.6(2.07-10.20)^{* *} \\
1.6(0.33-7.78)\end{array}$ \\
\hline
\end{tabular}

IADL, Instrumental Activities of Daily Living; ADL, Basic Activities of Daily Living. Model reference category $1 / 4$ no cognitive impairment and no depressive symptoms (NCOG-NDEP); model Chi-square test: 215.7; df 21; $p<0.001$. OR $1 / 4$ adjusted odds ratio (CI $1 / 4$ confidence interval). *Significant correlations are indicated in bold $\mathrm{p}<0.05$. $* * \mathrm{p}<0.001$.

Previous studies on community-based samples have not reported on the correlates of co-occurrence of cognitive impairment and depressive symptoms. To address the problem, comorbidity illnesses were assessed for their differential association with COG, DEP and COG-DEP. Our study clearly demonstrated that certain comorbidities reported in the CCI were specific to COG, DEP and COG-DEP. Nonetheless it must be considered before interpreting these findings that this cross-sectional study is not appropriate for drawing causal interferences. While it is likely that physical and psychological changes related to chronic medical conditions can cause cognitive impairment and/or depressive symptoms, COG and/or DEP may also worsen chronic medical conditions due to poor self-care. Despite the strength of this study, including large number of subjects, valid measurement instruments and adjustment for multiple potential con- founders, some limitations should nevertheless be pointed out. It cannot be excluded that the measurement of depressive symptoms could be confounded with the measurement of disability, with depressed elderly giving unrealistically pessimistic appraisals of their disabilities (Kempen et al., 1996). Additionally, chronic medical conditions were established using patients' reports, but Kriegsman et al. (1996) demonstrated that deviations in cognitive function and depressive symptomatology had no influence on the level of accuracy.

Primarily, our results showed that cancer was more prevalent in participants COG. This could be an indirect effect of health and psychological factors increasing vulnerability to cognitive dysfunction, as it is the case after chemotherapy for breast cancer (Vearncombe et al., 2009). Cognitive dysfunction is also a common occurrence among patients with small- 
cell lung cancer, although prophylactic cranial irradiation has been described as one explanation for these cognitive deficits (Meyers et al., 1995). Poor cognitive performance was also highly prevalent in patients with heart disease, stroke and diabetes (Breteler et al., 1994; Ferrucci et al., 1996; Strachan et al., 1997) and was not reported in our study of solely COG participants. Secondarily, some evidence suggests an association between DEP and connective tissue disease, visual limitation, ulcers and peripheral vascular disease. Studies show that patients with arthritis, visual limitation or gastrointestinal diseases often score highly on measures of depression (Jess and Eldrup, 1994; Ormel et al., 1997; Papadopoulos et al., 2005). The limited available data suggest that depression may precede the development of ulcers. Participants with peripheral vascular diseases seemed to experience more depressive symptoms than reported by other researchers, who rather stressed the importance of heart conditions and diabetes (Ormel et al., 1997; Charlson and Peterson, 2002). Thirdly, chronic medical conditions varied in the extent they were associated with COG-DEP. In this study, COG-DEP was experienced by patients with vision impairment, cerebrovascular disease, congestive heart failure, hearing impairment and diabetes. As previously described (Reuben et al., 1999), sensory impairment in the elderly was independently associated with IADL restriction in household maintenance activities, but not with cognitive performances. The chronic medical conditions cited above are commonly associated with depression alone or cognitive impairment alone rather than co-occurrence of both. The present results on COG, DEP and COG-DEP show the particular relevance of certain CCI conditions to those three distinct groups.

Elderly people with COG and/or DEP were shown to have significantly larger numbers of comorbidity conditions and to be polymedicated (6 drugs or more). This was more evident for DEP people for whom poorer outcomes remained significantly associated even after adjustment for socio-demographics and functional status. In the study by Penninx et al. (1999), depressive symptoms and comorbidity also predicted higher long-term mortality when controlling for comorbidity and physical function. Ultimately, patients with increased comorbidity were also shown to be at higher risk for functional deterioration in basic and instrumental activities of daily living, impairing their quality of life. Significant new research is needed to determine whether among patients with the greatest comorbidity and functional limitations, by preventing or treating new cognitive decline and/or depressive symptoms, morbidity and mortality also can be reduced. Additionally, if chronic medical conditions are interpreted as a risk for $\mathrm{COG}$ and/or DEP, they might help understanding the pathophysiology of depression and cognitively impairment. Inversely, if comorbidities are regarded as a consequence of cognitive impairment and/ or depressive symptoms, their presence could help the clinician in solidifying the diagnosis of $\mathrm{COG}$ and DEP.

\section{Conclusions}

Our findings suggest that elderly people with COG, DEP and COG-DEP should be carefully screened for associated chronic medical conditions, and vice versa. However, controlled trials are necessary to assess the impact this may have on service utilization. Additionally, if comorbidity is not adequately measured in COG and/ or DEP elderly people, there is an important potential for confounding. Studies must be designed with appropriate methodology to measure the independent impact of comorbidity disease on outcomes. Another potential direction for research is exploring medical illness in subtypes of depression and cognitive impairment.

\section{Conflict of interest}

None declared.

\section{Acknowledgements}

The authors sincerely thank the Naro'n Council for providing them access to their elderly people.

\section{Key Points}

- $\quad$ The co-occurrence of cognitive impairment and depressive symptoms (COG-DEP) was explained by IADL and ADL dependence, cerebrovascular disease, congestive heart failure and diabetes, but it was best predicted by functional limitations in the adjusted model.

- $\quad$ Being functionally dependent and medically ill with shorter life expectancy was shown to significantly increase the odds of being DEP.

- Functional limitation in IADL was without distinction associated to COG, DEP or both (COG-DEP). 


\section{References}

Agüero-Torres H, Thomas VS, Winblad B, Fratiglioni L. 2002. The impact of somatic and cognitive disorders on the functional status of the elderly. J Clin Epidemiol 55: 1007-1012. DOI: 10.1016/S0895-4356(02)00461-4.

American Psychiatric Association. 2001. Manual diagnóstico y estadístico de los trastornos mentales [Diagnostic and Statistical Manual of Mental Disorders],(4th edn) text revised. (DSM-IV-TR). Masson: Barcelona.

Armenian HK, Pratt LA, Gallo J, Eaton WW. 1998. Psychopathology as predictor of disability: a population-based follow-up study in Baltimore, Maryland. Am J Epidemiol 148: 269-275.

Artero S, Touchon J, Ritchie K. 2001. Disability and mild cognitive impairment: a longitudinal population-based study. Int J Geriatr Psychiatry 16: 1092-1097. DOI: $10.1002 / \mathrm{gps} .477$

Barnes DE, Alexopoulos GS, Lopez OL, Williamson JD, Yaffe K. 2006. Depressive symptoms, vascular disease, and mild cognitive impairment: findings from the cardiovascular health study. Arch Gen Psychiatry 63: 273-279.

Bassett SS, Folstein MF. 1991. Cognitive impairment and functional disability in the absence of psychiatric diagnosis. Psychol Med 21: 77-84. DOI: 10.1017/ S0033291700014677.

Beekman AT, Copeland JR, Prince MJ. 1999. Review of community prevalence of depression in later life. $\mathrm{Br} J$ Psychiatry 174: 307-311. DOI: 10.1192/bjp.174.4.307

Beekman AT, Deeg DJ, Braam AW, Smit JH, van Tilburg W. 1997. Consequences of major and minor depression in later life: a study of disability, well-being and service utilization. Psychol Med 27: 1397-1409. DOI 10.1017/S0033291797005734.

Breteler MM, Claus JJ, Grobbee DE, Hofman A. 1994. Cardiovascular disease and distribution of cognitive function in elderly people: the Rotterdam study. BMJ 308: $1604-1608$

Bulbena A, Berrios GE. 1993. Cognitive function in the affective disorders: a prospective study. Psychopathology 26: 6-12. DOI: 10.1159/000284794.

Charlson M, Peterson JC. 2002. Medical comorbidity and late life depression: what is known and what are unmet needs? Biol Psychiatry 52: 226-235. DOI 10.1016/ S0006-3223(02)01422-1.

Charlson ME, Pompei P, Ales KL, MacKenzie CR. 1987. A new method of classifying prognostic comorbidity in longitudinal studies: development and validation. J Chronic Dis 40: 373-383. DOI: 10.1016/0021-9681(87)90171-8.

Chen P, Ganguli M, Mulsant BH, DeKosky ST. 1999. The temporal relationship between depressive symptoms and dementia: a community-based prospective study. Arch Gen Psychiatry 56: 261-266. DOI: 10.1001/archpsyc.56.3.261.

Crum RM, Anthony JC, Bassett SS, Folstein MF. 1993. Population-based norms for the Mini-Mental State Examination by age and educational level. JAMA 269 : 2386- 2391

Duke University. 1978. Multidimensional Functional Assessment: The OARS Methodology, (2nd ed). Center for the Study of Aging and Human Development, Duke University: Durham, NC

Ferrucci L, Guralnik JM, Salive ME, et al. 1996. Cognitive impairment and risk of stroke in the older population. J Am Geriatr Soc 44: 237-241.

Folstein MF, Folstein SE, McHugh PR. 1975. "Mini-Mental State" a practical method for grading the cognitive state of patients for the clinician. J Psychiatry Res 12: 189- 198. DOI: 10.1016/0022-3956(75) 90026-6.

Forsell Y, Palmer K, Fratiglioni L. 2003. Psychiatric symptoms/syndromes in elderly persons with mild cognitive impairment. Data from a cross-sectional study. Acta Neurol Scand 107 (Suppl 179): 25-28. DOI 10.1034/j.1600-0404.107.s179.4.x

Gabryelewicz T, Styczynska M, Pfeffer A, et al. 2004. Prevalence of major an minor depression in elderly persons with mild cognitive impairment-MADRS factor analysis. Int $\mathrm{J}$ Geriatr Psychiatry 19: 1168-1172. DOI 10.1002 /gps. 1235 .

Herrmann N, Mittmann N, Silver IL, et al. 1996. A validation study of the geriatric depression scale short form. Int J Geriatr Psychiatry 11: 457-460. DOI 10.1002/ (SICI)1099-1166(199605)11:5<457::AID.-GPS325> 3.0.CO;2-2.

Holstein J, Chatellier G, Piette F, Moulias R. 1994. Prevalence of associated diseases in different types of dementia among elderly institutionalized patients: analysis of 3447 records. J Am Geriatr Soc 42: 972-977.

Jess P, Eldrup J. 1994. The personality patterns in patients with duodenal ulcer and ulcer-like dyspepsia and their relationship to the course of the diseases. J Intern Med

235. 589-594. DOI: 10.1111/j. 1365-2796. 1994 tb01266.x

Katz S, Ford AB, Moskowitz RW, Jackson BA, Jaffe MW. 1963. Studies of illness in the aged. The index of ADL: a standardized measure of biological and psychological function. JAMA 185: 914-919.

Kempen GI, Steverink N, Ormel J, Deeg DJ. 1996. The assessment of ADL among frail elderly in an interview survey: self-report versus performance-based tests and determinants of discrepancies. J Gerontol B Psychol Sci Soc Sci 51: 254-260. DOI: 10.1093 /geronb/51B.5.P254

Kessing LV. 1998. Cognitive impairment in the euthymic phase of affective disorder. Psychol Med 28: 1027-1038. DOI: 10.1017/S0033291798006862.

Kockler M, Heun R. 2002. Gender differences of depressive symptoms in depressed and nondepressed elderly persons. Int J Geriatr Psychiatry 17: 65-72. DOI: 10.1002/ gps.521.

Kriegsman DM, Penninx BW, van Eijk JT, Boeke AJ, Deeg DJ. 1996. Self-reports and general practitioner information on the presence of chronic diseases in community dwelling elderly. A study on the accuracy of patients' self-reports and on determinants of inaccuracy. J Clin Epidemiol 49: 1407-1417. DOI:
$10.1016 / \mathrm{S} 08954356(96) 00274-0$

Lawton MP, Brody EM. 1969. Assessment of older people: self-maintaining and instrumental activities of daily living. Gerontologist 9: 179-186. DOI: 10.1093/ geront/9.3_Part_1.179.

Lo“ppo“nen MK, Isoaho RE, Ra“iha“ IJ, et al. 2004. Undiagnosed diseases in patients with dementia-a potential target group for intervention. Dement Geriatr Cogn Disord 18: 321-329. DOI: 10.1159/000080126.

Luck T, Luppa M, Briel S, Riedel-Heller SG. 2010. Incidence of mild cognitive impairment: a systematic review. Dement Geriatr Cogn Disord 29: 164-175. DOI: $10.1159 / 000272424$

Lupien SJ, de Leon M, de Santi S, et al. 1998. Cortisol levels during human aging predict hippocampal atrophy and memory deficits. Nat Neurosci 1: 69-73. DOI: $10.1038 / 271$.

Lyketsos CG, Steinberg M, Tschanz JT, et al. 2000. Mental and behavioral disturbances in dementia: findings from the Cache County Study on Memory in Aging. Am J Psychiatry 157: 708-714. DOI: 10.1016/S0197-4580(00)83436-3.

Marcos T, Salamero M, Gutie'rrez F, et al. 1994. Cognitive dysfunctions in recovered melancholic patients. J Affect Disord 32: 133-137. DOI: 10.1016/01650327(94)90071-X

Meyers CA, Byrne KS, Komaki R. 1995. Cognitive deficits in patients with small cell lung cancer before and after chemotherapy. Lung Cancer 12: 231-235. DOI: 10.1016/0169-5002(95)00446-8

Millán-Calenti JC, Tubı́o J, Pita-Ferna'ndez S, et al. 2010. Prevalence of functional disability in activities of daily living (ADL), instrumental activities of daily living (IADL) and associated factors, as predictors of morbidity and mortality. Arch Gerontol Geriatr 50: 306-310. DOI: 10.1016/j.archger.2009.04.017.

Millán-Calenti JC, Tubı́o J, Pita-Ferna'ndez S, et al. 2009. Prevalence of cognitive impairment: effects of level of education, age, sex and associated factors. Dement Geriatr Cogn Disord 28: 455-460. DOI: 10.1159/000257086.

Morgado J, Rocha CS, Maruta C, Guerreiro M, Martins IP. 2010. Cut-off scores in MMSE: a moving target? Eur J Neurol 17: 692-695. DOI: 10.1111/j.14681331.2009.02907.x.

Ormel J, Kempen GIJM, Penninx BWJH, et al. 1997. Chronic medical conditions and mental health in older people: disability and psychological resources mediate specific mental health effects. Psychol Med 27: 1065-1077. DOI: 10.1017/ S0033291797005321.

Panza F, Frisardi V, Capurso C, et al. 2010. Late-life depression, mild cognitive impairment and dementia: possible continuum? Am J Geriatr Psychiatry 18:98116. DOI: $10.1097 /$ JGP.0b013e3181b0fa13

Papadopoulos FC, Petridou E, Argyropoulou S, et al. 2005. Prevalence and correlates of depression in late life: a population based study from a rural Greek town. Int J Geriatr Psychiatry 20: 350-357. DOI: 10.1002/gps.1288.

Penninx BW, Geerlings SW, Deeg DJ, et al. 1999. Minor and major depression and the risk of death in older persons. Arch Gen Psychiatry 56: 889-895. DOI: $10.1001 /$ archpsyc.56.10.889.

Reifler BV, Larson E, Hanley R. 1982. Coexistence of cognitive impairment and depression in geriatric outpatients. Am J Psychiatry 139: 623-626.

Reuben DB, Mui S, Damesyn M, Moore AA, Greendale GA. 1999. The prognostic value of sensory impairment in older persons. J Am Geriatr Soc 47: 930-935.

Sheikh JL, Yesavage JA. 1986. Geriatric Depression Scale (GDS). Recent evidence and development of a shorter version. Clin Gerontol 5: 165-172. DOI: 10.1300/ J018v05n01_09.

SPSS Inc. 2007. SPSS Base 16.0. Users' Guide. Prentice Hall: Chicago IL. Strachan MW, Deary IJ, Ewing FM, Frier BM. 1997. Is type II diabetes associated with an increased risk of cognitive dysfunction? A critical review of published studies. Diabetes Care 20: 438-445. DOI: 10.2337/diacare.20.3.438.

United Nations. 2009. World Population Ageing 2009. UN: Ginebra

Vearncombe KJ, Rolfe M, Wright M, et al. 2009. Predictors of cognitive decline after chemotherapy in breast cancer patients. J Int Neuropsychol Soc 15: 951-962. DOI: $10.1017 /$ S1355617709990567.

Vinkers DJ, Gussekloo J, Stek ML, Westendorp RG, van der Mast RC. 2004 Temporal relation between depression and cognitive impairment in old age: prospective population based study. BMJ 329: e881. DOI: 10.1136/bmj.38216.604664.DE.

Wells KB, Stewart A, Hays RD, et al. 1989. The functioning and well-being of depressed patients. Results from the medical outcomes study. JAMA 262: 914 919.

Wolf-Klein GP, Siverstone FA, Brod MS, et al. 1988. Are Alzheimer patients healthier? J Am Geriatr Soc 36: 219-224.

Zekry D, Herrmann FR, Grandjean R, et al. 2008. Demented versus non-demented very old inpatients: the same comorbidities but poorer functional and nutritional status. Age Ageing 37: 83-89. DOI: 10.1093/ageing/afm132.

Zung WWK. 1967. Depression in the normal aged. Psychosomatics 8: 287-292.

Zunzunegui MV, Minicuci N, Blumstein T, et al. 2007. Gender differences in depressive symptoms among older adults: a cross-national comparison: the CLESA project. Soc Psychiatry Epidemiol 42: 198-207. DOI: $10.1007 / \mathrm{s} 00127-0070158-3$ 